\title{
A statistical study of environmental influences on bivalve recruitment in the Wash, England
}

\author{
Emma F. Young*, Grant R. Bigg, Alastair Grant \\ School of Environmental Sciences, University of East Anglia, Norwich NR4 7TJ, England
}

\begin{abstract}
Recruitment of 2 commercially important bivalves in the Wash (England) is shown to be influenced by atmospheric circulation patterns and preceding winter (January and February) mean sea temperature anomaly. The availability of Lamb daily classifications of synoptic weather patterns over the British Isles permits correlations between weather patterns and fishery records for the past century. Cerastoderma edule (common cockle) recruitment was high when there was a high frequency of the Easterly Lamb circulation type during the months April to July, and in particular during June. This corresponds with a high frequency of easterly winds. It is hypothesised that these easterly winds induce currents which act as a mechanism to retain larvae close to suitable settlement sites. Mytilus edulis (common mussel) recruitment was not strongly affected by Lamb circulation types. However, cold winters were associated with increased mussel recruitment. Cold winters may reduce or delay predation due to crabs, thus reducing post-settlement mortality, and may also induce a reduction in maintenance metabolism, thus increasing the quality and quantity of larval production. These results suggest that events in the plankton may be an important determınant of $C$. edule populations, while they appear to be less important in structuring $M$. edulis communities
\end{abstract}

KEY WORDS: Mytilus edulis - Cerastoderma edule Supply side ecology · Commercial shellfish

\section{INTRODUCTION}

As understanding of the processes that structure marine populations has increased, it has become evident that recruitment can be a major influence on adult abundance. Thorson (1950) was one of the first ecologists to stress the importance of recruitment limitation to the variability of adult populations. He argued that planktotrophic larvae are more prone to variations in survival and settlement than lecithotrophic species or direct developers due to the hazardous nature of a planktonic life stage. However, Connell (1985) emphasized the importance of distinguishing between settlement, as the point when an individual first takes up permanent residence on the benthos, and recruitment. when the recently settled juveniles have survived for a period of time after settlement.

Larvae of marine invertebrates are extremely difficult to study in the field (Young \& Chia 1985), thus processes in the plankton are poorly understood. Field estimates of averaged daily mortality range from about

·E-mail:e.young@uea.ac.uk
$13 \%$ for Mytilus edulis (the common mussel) veligers (Jørgensen 1981) to about $19.6 \%$ for the pink shrimp Penaeus duodarum (Munro et al. 1968). Sources of planktonic mortality include failure of fertilisation, extremes of temperature and salinity, inadequate food inability to find a suitable substratum, and predation. Most researchers agree that predation is the most significant influence on larval mortality (Thorson 1966 , Young \& Chia 1985). Fertilisation success is likely to be very high in most cases (Young \& Chia 1985), so does not contribute greatly to larval mortality. Inadequate food may cause starvation or slow growth rates, thus increasing the length of the planktonic life stage and resulting in longer exposure to other risks. Suboptimum temperatures and salinities may also slow development (Bayne 1965, Tiews 1970), but are unlikely to directly cause mortality unless they exceed the extreme levels that larvae can withstand. Finding a suitable settlement site can be a serious problem for planktonic larvae. During the 'precompetent' period, when a larva is developing to a stage capable of settling, water motion can move it away from suitable benthic habitats. Thus, once it reaches the 'competent' 
phase, it may have to drift until it either reaches a suitable settlement site, or dies through predation or degeneration (Jackson \& Strathmann 1981).

A number of studies argue that the community ecology of some rocky shores may be governed by limitations to the supply of larvae reaching the site (Lewis 1972, Underwood \& Fairweather 1989), in particular as a result of hydrographic features in the coastal waters (Kendall et al. 1982, Roughgarden et al. 1994). However, Roughgarden et al. (1988) noted that post-settlement processes were more important at some sites. Spatial variation in the dominance of pre- or postsettlement processes was attributed to the regional pattern of circulation in the coastal waters. Some marine larvae have behavioural adaptations which allow them to control their movement due to oceanographic influences, In estuaries, where riverine influx implies a net seaward transport of larvae, some species have developed a process of selective swimming which is correlated with the increases in salinity on a flood tide (Wood \& Hargiss 1971). However, the vertical homogeneity of the Wash (England) implies that such behavioural adaptations are unlikely in this region.
By contrast, Wildish (1977) suggested that the composition, biomass and productivity of sublittoral macrofaunal communities were regulated by a hierarchy of multiple limiting factors, and an extensive review of communities in marine soft sediments led Olaffson et al. (1994) to conclude that pre-settlement processes were not important for the shaping of these communities and that multiple post-settlement processes exist which have the potential to obliterate the effects of settlement variation. However, they noted that no definitive study was available which clearly tested the importance of limitations in larval supply by partitioning community development into pre- and post-settlement processes.

As part of the fisheries conservation effort, the Eastern Sea Fisheries Joint Committee has a long historical record of Cerastoderma edule (the common cockle) and Mytilus edulis recruitment in the Wash (Fig. 1), showing high interannual variability. The Wash is a semi-enclosed system with no other large populations of these species nearby. These records therefore provide an excellent opportunity to assess the effect of environmental variability on recruitment success.

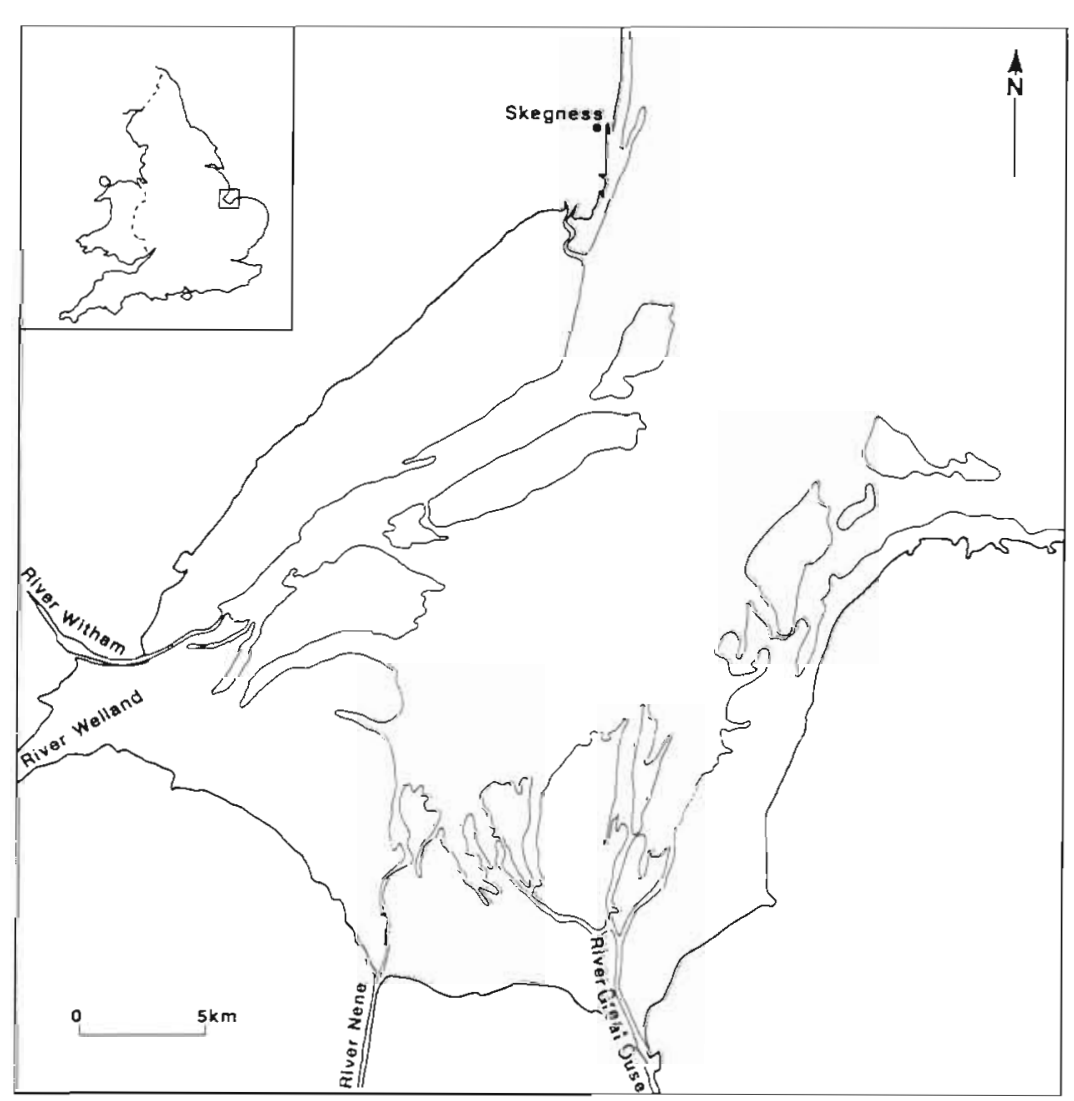

Fig. 1. Location and main physical characteristics of the Wash, England, where the lighter line shows the level of zero height at lowest astronomical tide

\section{Description of study area}

The Wash (Fig. 1) is the remnant of a large depression cut into the Jurassic clays of eastern England by fluvial and glacial action during the Quaternary (Evans \& Collins 1987). It receives the drainage of about $12500 \mathrm{~km}^{2}$ of eastern England through the Great Ouse, Nene, Welland and Witham river systems. However, it is in essence a large bay rather than an estuary. Of its area of about $620 \mathrm{~km}^{2}$, nearly half $\left(290 \mathrm{~km}^{2}\right)$ is permanently covered by water, the remainder consists of a broad belt of marshes, mudflats and sandflats.

There is a general anticlockwise pattern of water circulation in the North Sea with residual wator flow towards the south-east in the southern North Sea adjacent to the Wash (Salomons et al. 1988). Water flows within the Wash are dominated by strong semi-diurnal tides with a mean tidal range of approximately $5 \mathrm{~m}$ and peak flood current speeds in the centre of the embayment in excess of $1.5 \mathrm{~m} \mathrm{~s}^{-1}$ (HRS 1972). Residual currents in the embayment show a distinct lateral inhomogeneity, whereas vertically the 
water column is almost homogeneous (Ke et al. 1996). The central deep water area is dominated by a residual south-westwards water movement, whilst on the margins, the residual movement is north-eastwards.

Historically, there have been a number of important commercial fisheries in the Wash. For example, in 1987 landings in the Wash alone were $35 \%$ (cockle), $70 \%$ (mussel) and $85 \%$ (shrimp) of total such landings in the UK (Aldous 1987), demonstrating both the national and local importance of the fisheries. However, catches of these shellfish in the Wash show large interannual variability, with associated economic repercussions. In addition, the mussel fishery has suffered a serious decline, with landings in the Wash falling from $6872 \mathrm{t}$ in 1989 (76\% of UK landings) to just $25 \mathrm{t}$ in 1994 (0.2\% of UK landings) (HMSO London 1991, 1994, Chris Beach, Eastern Sea Fisheries, pers. comm.). A preliminary study (Dare \& Walker 1992) suggested that changes in the environment may be responsible for variations in shellfish fishery yields. The mean sea temperature during the period of gametogenesis was suggested as a possible influence on the quality and quantity of egg production. Additionally, the 3 most economically important shellfish species, the brown shrimp Crangon crangon, the common cockle Cerastoderma edule and the common mussel Mytilus edulis, have a planktonic larval phase. The transport and retention of the larvae close to suitable settlement sites is controlled by the water currents and may therefore be affected by wind direction and magnitude.

\section{METHODS}

Indices of larval spatiall. The Eastern Sea Fisheries Joint Committee, which is responsible for the management of local fisheries, produces annual reports which provide a historic record of spatfall occurrence and stock abundance of Cerastoderma edule and Mytilus edulis in the Wash, dating from 1920. The brown shrimp is also of major commercial importance in the Wash but there are no comparable data available for this species as it does not have a sedentary life stage. Hence the brown shrimp was not considered in this study. Spatfall includes both settlement and the preliminary survival (about $3 \mathrm{mo}$ ) of the settled larvae. The information available is mainly descriptive, but it is given in a sufficiently standard form that it provides useful indices of spatfall frequency and magnitude which have been categorized by the Ministry of Agriculture, Fisheries and Food (MAFF) in the form of an ordinal, non-parametric 5point scale, ranging from 'nil' to 'very heavy' (Dare \& Walker 1992). Although qualitative, these data have the potential to provide useful insights into the broad pattern of influences on the annual variation of larval spatfall in the Wash.

Two influences were of particular interest. Dare \& Walker (1992) showed that mean sea temperature during the period of gametogenesis (winter) had some effect on spat abundance; the present study aimed to clarify these results. Dare \& Walker (1992) also suggested that larval spatfall in the Wash is influenced by meteorological conditions, in particular wind direction and magnitude. Their initial study, using a coarsescale resolution of wind direction, duration and velocity, found no connection between wind forcing and annual variations in spat abundance. It was concluded that more detailed analyses of the data were required

There were insufficient wind data available for the Wash region to enable a statistical study of the effect of winds on spatfall. However, daily Lamb circulation classifications were available from the Climatic Research Unit at the University of East Anglia. If the association between these and mean daily wind direction in the Wash is strong, they can be used as a surrogate for wind data.

Lamb circulation classifications and surface winds. Meaningful conclusions relating surface winds to larval spatfall cannot be drawn unless there is a good correlation between surface wind direction and Lamb circulation type. Therefore, the relationships between surface winds near the Wash and the Lamb classification types were investigated.

Lamb synoptic classifications: Lamb (1972) developed a synoptic-scale, daily weather-map classification for use over the British Isles, and used the scheme to produce a record of daily classifications dating from 1861 to the present day. This is a manually derived synoptic classification, whereby 7 basic types are recognised.

Anticyclonic types (A) feature highs centred over, near or extending over the British Isles. Cyclonic types (C) have depressions centred over Britain or Ireland at some point during the day. Westerly conditions (W) occur when high pressure is to the south of the British Isles and low pressure is to the north. Sequences of depressions and ridges are steered eastwards across the Atlantic and Britain by the resulting zonal flow. North-westerly types (NW) are associated with the displacement of the Azores anticyclone either north-east towards the British Isles or north over the Atlantic west of the coast. Depressions are steered around the flow, travelling south-east into the North Sea. Northerly days $(\mathrm{N})$ have high pressure to the west and northwest of Britain, with low pressure over the Baltic, Scandinavia and the North Sea. Depressions are steered southwards. Easterly types (E) are characterized by anticyclones over, or extending over, Scandinavia and towards Iceland. Depressions are restricted to the western North Atlantic and the vicinity of the Iberian 
peninsula. Southerly types (S) result from high pressure covering central and northern Europe. Atlantic depressions are blocked west of the British Isles.

Lamb (1972) also identified unclassifiable days and hybrid types. Unclassifiable days are those with either weak or chaotic patterns, small-scale systems of unlike character, or rapid change of the situation over the British Isles region within the day. Hybrid types satisfy the definitions of more than 1 individual type. The use of hybrid types reduced the number of unclassifiable days and aimed to make the scheme more objective by preventing the forcing of daily weather patterns into ill-fitting classes. In total, the scheme has 27 types. Lamb (1972) suggested that for statistical purposes. hybrid days could be counted as a half or a third (depending on the hybrid) to each of the types represented. Jones \& Kelly (1982) investigated this idea more thoroughly with principal component analysis and found that most of the temporal variance in the Lamb weather-type catalogue was accounted for by 6 of the 27 categories, and that these were basic types

A number of studies have attempted to find relationships between Lamb types and surface weather conditions. Jones \& Kelly (1982) found weak but physically reasonable correlations between their principal components and central England temperatures. The Cyclonic, Anticyclonic and Westerly types were found to be associated with rainfall quantity and variance in England and Wales (Wigley \& Jones 1987). In their work on wind-energy potential in Britain, Palutikof et al. (1987) found that there is a relationship between wind speed and the frequency of the Anticyclonic and Westerly types. Lamb (1972) found that the correlation between the frequencies of south-westerly surface winds at or near London and the frequency of the Westerly type was not very high. However, his study was not extended to any of the other Lamb types.

Surface wind data: Hourly mean wind directions and magnitudes at Marham, Norfolk, located approximately $20 \mathrm{~km}$ south-east of the mouth of the River Great Ouse, were provided by the Meteorological Office and acquired by MAFF. Seven years of data for the months April to July were made available: 1978 , $1980,1984,1985,1986,1988,1993$. The categorising of hourly wind directions into a mean daily wind direction suggested 3 possible ways to classify a given day. This is illustrated for a daily mean easterly surface wind: (1) The direction of the mean daily wind vector was between $45^{\circ}$ and $135^{\circ}$. (2) The direction of the mean daily wind vector was greater than $0^{\circ}$ and less than $180^{\circ}$. (3) Twelve or more of the hourly mean wind directions were between $45^{\circ}$ and $135^{\circ}$.

In order to determine the most appropriate definition, the relationship between easterly surface winds as depicted by the above categories and the Easterly
Lamb circulation type was investigated using a $\chi^{2}$ test. In addition to the 3 types of classification of the surface winds, each day could be considered as having an Easterly Lamb type if it was assigned either the basic Easterly type, or one of the hybrid Easterly types. Thus one test only counted the days assigned the basic Easterly type and a second test counted days assigned either the basic type or one of the hybrid Easterly types. All 6 tests gave $\chi^{2}$ values exceeding the $99.9 \%$ significance level. Given the high correlations with all 3 definitions of daily mean easterly surface wind, the less restrictive definition 2 was thought inappropriate Of the other 2 categorisation techniques, method 1 was chosen over method 3 for its computational simplicity The direction of the mean surface winds was therefore categorised as follows (the north-westerly direction is included for comparison with the North-westerly Lamb type): easterly, the direction of the mean daily wind vector was between $45^{\circ}$ and $135^{\circ}$; southerly, the direction of the mean daily wind vector was between $135^{\circ}$ and $225^{\circ}$; westerly, the direction of the mean daily wind vector was between $225^{\circ}$ and $315^{\circ}$; northerly, the direction of the mean daily wind vector was between $315^{\circ}$ and $45^{\circ}$; north-westerly, the direction of the mean daily wind vector was between $270^{\circ}$ and $360^{\circ}$

Table 1 shows a summary of the number of days with easterly, southerly, westerly, north-westerly or northerly surface wind direction observed on days with either one of the 7 basic Lamb circulation types or one of the hybrid types during the 7 years studied. Each hybrid is split into its basic type constituents. For example, the Anticyclonic Easterly hybrid would be counted as both an Anticyclonic day and an Easterly day. If only the basic Lamb types are considered, the pattern of distribution of surface wind directions is very similar.

Table 1 Summary showing the distribution of surface wind direction (E: easterly; S: southerly; W: westerly; NW: northwesterly; $N$ : northerly) at Marham in relation to the 7 basic Lamb types (A: Anticyclonic; E: Easterly; S: Southerly; W: Westerly; NW: North-westerly; N: Northerly; C: Cyclonic), where days with hybrid types have been counted as each of the basic type constituents

\begin{tabular}{|c|c|c|c|c|c|c|}
\hline \multirow[t]{2}{*}{ Lamb type } & \multicolumn{5}{|c|}{ Observed surface wind direction } & \multirow[t]{2}{*}{ Total } \\
\hline & $E$ & $S$ & W & NW & $N$ & \\
\hline A & 70 & 39 & 44 & 64 & 110 & 262 \\
\hline E & 71 & 16 & 0 & 10 & 62 & 149 \\
\hline $\mathrm{s}$ & 29 & 60 & 5 & 1 & 2 & 96 \\
\hline W & 0 & 48 & 81 & 34 & 4 & 133 \\
\hline NW & 0 & 0 & 42 & 25 & 13 & 55 \\
\hline $\mathrm{N}$ & 6 & 2 & 14 & 57 & 85 & 107 \\
\hline C & 30 & 92 & 54 & 28 & 28 & 204 \\
\hline Total & 166 & 214 & 226 & 200 & 249 & \\
\hline
\end{tabular}


The relationship between mean daily wind direction as defined above and the associated Lamb type was investigated, first counting only the days assigned the basic type, and then counting days assigned either the basic or hybrid types. The results are shown in Table 2. It can be seen that mean daily surface wind direction at Marham is strongly related to the associated Lamb classification type for all 5 direction categories. Comparison with Table 1 shows that, in each case, surface wind direction is observed to coincide with the associated Lamb type with much greater frequency than would be expected if there were no relationship.

The study was extended to investigate the relationships between mean daily surface winds and the Cyclonic and Anticyclonic types which, from their definition, are associated with variable wind direction. Days assigned either the basic or hybrid types were considered and the results are shown in Table 3. It can be seen that the Anticyclonic and Cyclonic Lamb types are more strongly associated with some surface wind directions than with others. In particular, fewer southerlies and westerlies and more northerlies were observed on days assigned the Anticyclonic type than would be expected if the wind direction were totally random. On days assigned the Cyclonic type, fewer easterlies, northerlies and northwesterlies and more southerlies were observed than expected

In conclusion, comparisons of mean daily surface winds at Marham and Lamb classification types show that there is a strong relationship between these parameters. It can therefore be assumed that the Easterly, Southerly, Westerly, Northerly and Northwesterly Lamb types are reasonable indicators of easterly, southerly, westerly, northerly and northwesterly mean daily surface wind directions respectively.

Table 2. Chi-squared test results for mean surface wind direction and the associated Lamb classification type

\begin{tabular}{|llrc|}
\hline $\begin{array}{l}\text { Surface wind } \\
\text { direction }\end{array}$ & $\begin{array}{c}\text { Associated Lamb } \\
\text { type classification }\end{array}$ & $\chi^{2}$ & $\begin{array}{c}\text { Significance } \\
\text { level (\%) }\end{array}$ \\
\hline Easterly & Basic & 30.397 & 99.9 \\
Southerly & Basic + Hybrid & 73.996 & 99.9 \\
Westerly & Basic & 7.030 & 99.0 \\
& Basic + Hybrid & 65.479 & 99.9 \\
Northerly & Basic & 58.439 & 99.9 \\
& Basic + Hybrid & 76.734 & 99.9 \\
North-westerly & Basic & 34.914 & 99.9 \\
& Basic + Hybrid & 125.437 & 99.9 \\
& Basic + Hybrid & 58.279 & 99.9 \\
& & 95.692 & 99.9 \\
\hline
\end{tabular}

Shellfish spatfall and environmental influences. Spatfall of mussels and cockles in the Wash may be influenced by environmental factors, in particular the mean sea temperature during the period of gametogenesis (winter) and wind direction and magnitude during the periods of larval drift (spring and early summer) Larval spatfall may also be influenced by biotic variables such as predation, temperature, salinity and the supply of water borne food. However, these were not considered in this study due to the lack of available observational data. The data used to investigate the environmental influences of winds and mean sea temperature will now be described.

Wind direction: As shown earlier, daily circulation classifications are reasonable indicators of mean daily surface wind direction near the Wash, and this was assumed for this study. No information was available on the precise timing of the larval phase in each year so the 4 most likely months were considered, namely April to July (Savage 1956, Rasmussen 1973). As suggested by Lamb (1972), hybrid Lamb types were split into their basic components and counted as a half or a third to each of the types represented, depending on the hybrid. Frequencies of the 7 basic Lamb types during each month of the suggested larval phase and for the 4 months combined were then calculated for each year of available spatfall data.

Mean winter sea temperature: Mean winter sea temperatures (January and February) were supplied by MAFF (Peter Walker pers. comm.) for the years 1920-1992 with the exception of 1923, 1940-1946 and 1949 when data were missing. Monthly averages of air and sea temperatures were available for Skegness, just outside the north entrance to the Wash (Fig. 1) from 1966. Prior to 1966 , only air temperatures were recorded so sea temperatures $\left(t_{\text {sea }}\right)$ were estimated from the regression of sea on air temperature $\left(t_{\mathrm{arr}}\right)$, where temperatures are measured in ${ }^{\circ} \mathrm{C}$ (Dare \& Walker 1992):

Table 3. Chi-squared test results for Anticyclonic and Cyclonic Lamb types and mean surface wind direction. See Table 1 for abbreviations

\begin{tabular}{|lcrc|}
\hline $\begin{array}{l}\text { Lamb type } \\
\text { classification }\end{array}$ & $\begin{array}{c}\text { Surface } \\
\text { wind direction }\end{array}$ & $\chi^{2}$ & $\begin{array}{c}\text { Significance } \\
\text { level (\%) }\end{array}$ \\
\hline A & E & 5.702 & 97.5 \\
& S & 8.771 & 99.5 \\
& W & 36.037 & 99.9 \\
& NW & 4.205 & 95.0 \\
C N & 12.568 & 99.9 \\
& E & 10.339 & 99.5 \\
& S & 51.811 & 99.9 \\
& W & 0.020 & 10.0 \\
& NW & 48.019 & 99.9 \\
& N & 26.495 & 99.9 \\
\hline
\end{tabular}




$$
t_{\text {sea }}=0.5368 t_{\mathrm{alr}}+2.2212 \quad(\mathrm{r}=0.8030)
$$

Dare \& Walker (1992) found that mean air temperatures at Skegness compared well with those at 2 inland sites just south of the main Wash shellfish stocks, showing less than $0.5^{\circ} \mathrm{C}$ difference. They assumed, therefore, that mean sea temperature in the south of the Wash at high water was likely to be within $0.5^{\circ} \mathrm{C}$ of that at Skegness, although additional cooling could have been expected in the Wash during periods of severe frosts when intertidal populations were exposed.

Temperature data were supplied as positive or negative anomalies about the long-term mean at Skegness where, for the winter months January and February, a $1^{\circ} \mathrm{C}$ air temperature anomaly corresponded to a sea temperature anomaly of $0.5^{\circ} \mathrm{C}$ from the bi-monthly mean of $4^{\circ} \mathrm{C}$.

Statistical methods. General features in the data were investigated using analysis of variance (ANOVA). However, as the data are on an ordinal scale, more detailed analyses were carried out by fitting generalised linear models, using GLIM (Generalised Linear Interactive Modelling) (Crawley 1993). Straightforward linear regression methods are not strictly appropriate for categorical data as the linear model might lead to the prediction of negative and therefore non-existent categories. In GLIM, binary data such as the good/bad divisions described below can be handled very elegantly by using binomial errors and a log link (Crawley 1993); therefore this approach was used for verification of the results from the initial study.

GLIM can also be used to consider the effects of several factors at once. In this way, it was possible to look at the effects of both sea temperature and frequency of the 7 basic Lamb types concurrently, again using binomial errors and a log link. As mentioned earlier, mean winter sea temperature data were missing for a num- ber of years, so these analyses were repeated, first including and then excluding the years with missing temperature data. However, no further significant correlations were found with either of these last analyses.

Analyses. The relationships of spatfall indices with the frequency of the 7 basic Lamb types and the preceding winter mean sea temperature anomaly were investigated for both mussel and cockle larvae for the years 1920 to 1989. The spatfall indices were compared with the frequency of each basic Lamb type both for the months April to July combined and for each of these months separately. The indices were considered either on the full 5-point scale or split into 2 categories: good or bad. In the latter case, 2 possible divisions of the 5-point scale were used: (A) BAD representing nil, light and moderate years, GOOD representing heavy and very heavy years; (B) BAD representing nil and light years, GOOD representing moderate, heavy and very heavy years.

All the results which were significant at the $90 \%$ confidence level or more are recorded in Tables 4 (cockles) \& 5 (mussels).

\section{RESULTS}

ANOVA found a relationship between the 5-point index of cockle spatfall and the frequency of the Westerly Lamb type in April and an inverse relationship between the same spatfall index and the preceding winter mean sea temperature anomaly. However, visual inspection of the distribution showed that the correlation was a result of data from only 3 yr in index 5 (very heavy spatfall). The observed relationships may therefore be spurious.

ANOVA also found a relationship between mussel spatfall division $A$ and the frequency of the Westerly Lamb type in April. However, not only was this not duplicated by GLIM, it was not apparent with either

Table 4. Cerastoderma edule. Summary of the environmental influences on cockle spatfall found to be significant at the $90 \%$ confidence limit or greater

\begin{tabular}{|c|c|c|c|c|c|c|c|}
\hline $\begin{array}{l}\text { Spatfall } \\
\text { index }\end{array}$ & $\begin{array}{l}\text { Environmental } \\
\text { influence }\end{array}$ & Correlation & $\begin{array}{l}\text { ANOVA } \\
\text { F-ratio }\end{array}$ & $\begin{array}{l}\text { Confidence } \\
\text { level }(\%)\end{array}$ & Correlation & $\begin{array}{l}\text { GLIM } \\
\text { t-value }\end{array}$ & $\begin{array}{c}\text { Confidence } \\
\text { level }(\%)\end{array}$ \\
\hline 5-point & Lamb type A (Apr-Jul) & Negative & 2.61 & 95 & - & - & - \\
\hline Division $\mathrm{A}$ & Lamb type A (Apr-Jul) & Negative & 3.88 & 90 & Negative & 1.8907 & 90 \\
\hline 5-point & Lamb type E (Jun) & Positive & 3.75 & 97.5 & - & - & - \\
\hline Division A & Lamb type E (Jun) & Positive & 5.83 & 97.5 & Positive & 2.1405 & 95 \\
\hline Division $B$ & Lamb type E (Jun) & Positive & 4.16 & 95 & Positive & 1.8930 & 90 \\
\hline Division A & Lamb type E (Apr-Jul) & Positive & 4.68 & 95 & Positive & 2.0146 & 95 \\
\hline 5-point & Lamb type W(Apr) & Positive & 4.21 & 99 & - & - & - \\
\hline 5-point & Sea temp anomaly & Negative & 5.18 & 99 & - & - & - \\
\hline
\end{tabular}


spatfall division $B$ or the full 5-point spatfall index in ANOVA. Hence this relationship is likely to be spurious.

ANOVA revealed an inverse relationship between the 5-point cockle spatfall index and the frequency of the Anticyclonic Lamb type in the months April to July. Using GLIM, a similar inverse correlation was found with cockle spatfall division $A$. This suggests that the Anticylonic Lamb type may be an important influence on cockle spatfall in the Wash.

An inverse correlation between the mussel spatfall 5-point index and preceding winter (January and February) mean sea temperature anomaly was found by ANOVA. In addition, inverse correlations between spatfall divisions $A$ and $B$ and the mean sea temperature were observed with both ANOVA and GLIM.

ANOVA showed a significant relationship between the cockle spatfall 5-point index and the frequency of the Easterly Lamb type in June. Both ANOVA and GLIM found significant relationships between (1) cockle spatfall division $A$ and the frequency of the Easterly Lamb type during the months April to July, (2) cockle spatfall divisions $A$ and $B$ and the frequency of the Easterly Lamb type in June, and (3) mussel spatfall division $\mathrm{A}$ and the frequency of the Easterly Lamb type in June. The frequency of the Easterly Lamb type, particularly in June, is therefore an important factor in improving the quality of cockle and, to a lesser extent, mussel spatfall.

\section{DISCUSSION}

The Wash is a semi-enclosed sea with no other large populations of Mytilus edulis and Cerastoderma edule nearby, suggesting a necessarily discrete, self-sustaining system. Processes in the plankton are therefore more likely to have an observable effect on larval recruitment, which makes the Wash an ideal site for assessing the effects of environmental variability on recruitment success. As a result of the statistical analyses discussed above, a number of important environmental factors can be isolated.
Cold winters appear to improve the quality of mussel spatfall. Several reasons for this can be hypothesised. Mytilus edulis is resistant to cold temperatures (Beukema 1979) and is thought to experience a reduction in maintenance metabolism which releases more energy reserves for gametogenesis (Dare \& Walker 1992). After cold winters, the production of larvae from adult beds is therefore likely to be increased, and the survival of thesc larvae to be enhanced. Cold winters may also reduce or delay predation due to crabs, thus reducing post-settlement mortality (Beukema 1991). Hence after a cold winter, the initial larval concentration may be increased and spat mortality will be reduced, suggesting an increase in the quality of $M$. edulis spatfall.

There is also a possibility that extremely cold winters may increase Cerastoderma edule spatfall. All 3 years of very heavy cockle spatfall coincided with years experiencing significant negative temperature anomalies. Two of these years had the coldest mean winter sea temperatures of the period studied. However, as there were only 3 years with very heavy cockle spatfall, it is difficult to draw meaningful conclusions. A previous study of cockles in the Wash (Dare \& Walker 1992) found an inverse correlation between spat abundance and the size of the adult stock. This densitydependent control of recruitment by older cockles was also documented by Hancock (1973) following a study of cockle recruitment in Burry Inlet and by Beukema (1983) following an extensive study of bivalves in the Wadden Sea. The survival of cockles on the tidal flats of the Wadden Sea was observed to be reduced during winters that were colder than average (Beukema 1979). It is therefore hypothesised that very cold winters may enhance the survival of spat by removing many of the older cockles that would otherwise compete with spat for space, food and other resources.

Cockle spatfall was found to be influenced by 2 of the Lamb circulation types. High frequencies of the Anticyclonic type in the months April to July appear to reduce the quantity of spatfall. Although it was found earlier that the Anticyclonic type is associated with an increased frequency of northerly winds and a decrease

Table 5. Mytilus edulis. Summary of the environmental influences on mussel spatfall found to be significant at the $90 \%$ confidence level or greater

\begin{tabular}{|c|c|c|c|c|c|c|c|}
\hline $\begin{array}{l}\text { Spatfall } \\
\text { index }\end{array}$ & $\begin{array}{l}\text { Environmental } \\
\text { influence }\end{array}$ & Correlation & $\begin{array}{c}\text { ANOVA } \\
\text { F-ratio }\end{array}$ & $\begin{array}{c}\text { Confidence } \\
\text { level }(\%)\end{array}$ & Correlation & $\begin{array}{l}\text { GIIM } \\
\text { t-value }\end{array}$ & $\begin{array}{c}\text { Confidence } \\
\text { level }(\%)\end{array}$ \\
\hline Division $\mathrm{A}$ & Lamb type E (Jun) & Positive & 4.64 & 95 & Positive & 1.9553 & 90 \\
\hline Division A & Lamb type W (Apr) & Positive & 4.35 & 95 & - & - & - \\
\hline 5-point & Sea temp anomaly & Negative & 4.85 & 99 & - & - & - \\
\hline Division $\mathrm{A}$ & Sea temp anomaly & Negative & 9.25 & 99 & Negative & 2.5223 & 99 \\
\hline Division $B$ & Sea temp anomaly & Negative & 11.25 & 99 & Negative & 2.8137 & 99 \\
\hline
\end{tabular}


in the frequency of southerlies and westerlies, none of the other Lamb types associated with these wind directions were found to have a significant effect on spatfall. In addition, the Anticyclonic type is associated with light winds, so wind induced currents are likely to be of low magnitude. Hence, it is unlikely that the surface wind directions associated with this type are the important factor in the reduction of spatfall quality. However, the Anticyclonic type is associated with warm, dry weather (Lamb 1972), so a high frequency of this type may cause an increase in mortality of beached spat by desiccation or by inducing heat stress in juveniles, thus producing the observed inverse correlation.

High frequencies of the Easterly Lamb type in the months April to July, and particularly in June, are associated with an increase in cockle spatfall (Fig. 2). Lamb circulation types are reasonable indicators of mean daily surface wind direction, so it can be assumed that high frequencies of easterly surface winds will also be associated with an increase in cockle spatfall, possibly by inducing currents which act as a mechanism to retain larvae close to suitable settlement sites. Verification of this hypothesis using a hydrodynamic model is the subject of current work (E. Young unpubl.). High frequencies of the Easterly Lamb type in June are also associated with an increase in mussel spatfall for the same reason given above. However, mussel recruitment does not appear to be affected by wind-induced events in the plankton as greatly as that of cockles. The release of Mytilus edulis larvae does not show a highly defined peak but is spread over several months. It is therefore likely that individual wind events do not have a large effect on the overall annual recruitment level. In addition. in a study of $M$. edulis in the Menai Straits,

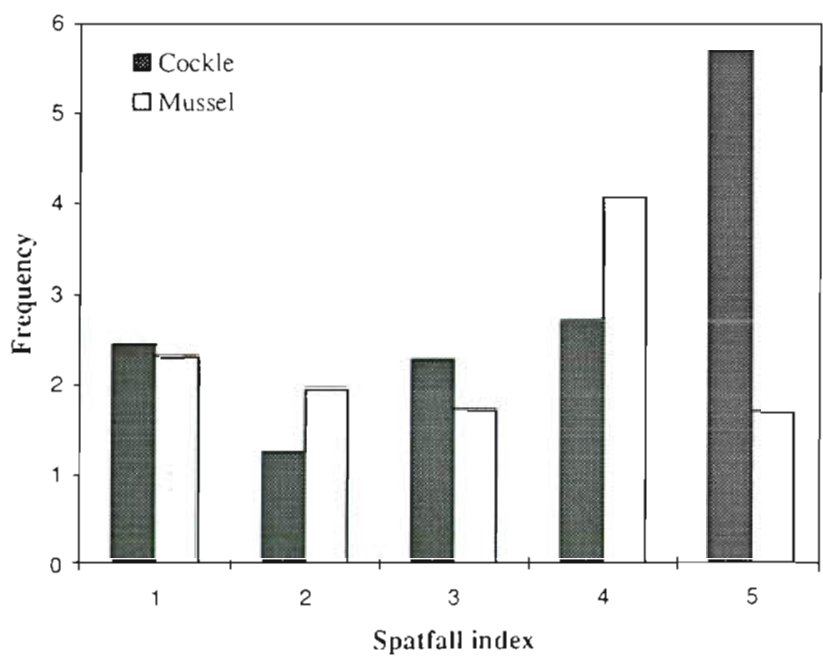

Fig. 2. Relationships between the mean frequency of the Easterly Lamb type in June and cockle and mussel spatfall indices (5-point scale ranging from nil to very heavy)
North Wales, Bayne (1964) found that competent larvae settle primarily onto filamentous substrata away from adult mussel beds where they grow to about $1.5 \mathrm{~mm}$ in size before migrating and undergoing secondary settlement on adult beds. Filamentous substrata such as the bryozoan Flustra foliacea and the hydroid Obelia dichotoma are found in areas of the Wash where Sabella pavonina tubes provide suitable attachment points (Fowler 1987). This was proposed as a mechanism for reducing competition between very young and adult mussels, but it also results in spreading the time competent larvae spend at the mercy of the water currents over a longer period, thus reducing the possible effects of individual wind events. A similar hypothesis was proposed by Thiebaut et al. (1994) who, in a study of larval transport in the Bay of Seine (France), found that wind action had little effect on the residual transport of Owenia fusiformis larvae, with a larval stage of about $1 \mathrm{mo}$, but a substantial effect on the transport of Pectinaria koreni larvae, with a larval life of only $2 \mathrm{wk}$.

An extensive review of previous studies of marine soft sediment communities (Olaffson et al. 1994) concluded that pre-settlement processes were not important for the shaping of these communities. In this study, some postsettlement processes were found to influence Cerastoderma edule recruitment, such as mortality through desiccation or heat stress in juveniles, and reduced competition between adults and young larvae after very cold winters. However, the most significant influence on C. edule recruitment in the Wash is a pre-settlement process; an increased frequency of easterly winds during the planktonic life stage induces currents which enhance the retention of larvae close to suitable settlement sites.

Roughgarden et al. (1994) argued that the structure of some rocky intertidal communities may be governed by pre-settlement processes, in particular limitations to the supply of larvae reaching the site due to events in the offshore waters. However, this study found that Mytilus edulis recruitment was not strongly affected by wind-induced events in the plankton. Mussels have been found to undergo a preliminary settlement on filamentous substrata away from adult beds (Bayne 1964) which results in prolonged exposure to water currents before the final settlement on adult beds. An individual wind event is therefore unlikely to have a great effect on the residual transport and recruitment of $M$. edulis larvae. However, mussel recruitment was strongly affected by preceding mean winter sea temperature. Cold winters enhance recruitment either by a reduction or delay in crab predation (Beukema 1991) or possibly by a reduction in maintenance metabolism releasing more energy reserves for gametogenesis (Dare \& Walker 1992). It is concluded that wind-driven transport of mussel larvae is not an important influence on the $M$. edulis population in the Wash. 
Acknowledgements. The authors thank Peter Walker, Peter Dare and Colin Bannister at the Ministry of Agriculture, Fisheries and Food for their advice and assistance; Phil Jones at the Climatic Research Unit, University of East Anglia for supplying Lamb circulation types; Natural Environment Research Council for funding via grant GT/4/93/152/A.

\section{LITERATURE CITED}

Aldous JR (1987) The commercial sea fisheries in the Wash. In: Doody P, Barnett B (eds) The Wash and its environment. Nature Conservancy Council, Peterborough, p $93-96$

Bayne BL (1964) Primary and secondary settlement in Mytulus edulis L. (Mollusca). J Anim Ecol 33:513-523

Bayne BL (1965) Growth and the delay of metamorphosis of the larvae of Mytilus edulis (L.). Ophelia 2(1):1-47

Beukema JJ (1979) Biomass and species richness of the macrobenthic animals living on a tidal flat area in the Dutch Wadden Sea: effects of a severe winter Neth $J$ Sea Res 13(2): 203-223

Beukema JJ (1983) Annual variation in reproductive success and biomass of the major macrozoobenthic species living in a tidal flat area of the Wadden Sea. Neth J Sea Res 16: $37-45$

Beukema JJ (1991) The abundance of shore crabs (Carcinus maenas (L.)) on a tidal flat in the Wadden Sea after mild and cold winters. J Exp Mar Biol Ecol 153:97-113

Connell JH (1985) The consequences of variation in initial settlement vs. post-settlement mortality in rocky intertidal communities. J Exp Mar Biol Ecol 93:11-45

Crawley MJ (1993) Methods in ecology: GLIM for ecologists. Blackwell Scientific, Oxford

Dare PJ, Walker P (1992) Spatfall and stock abundance fluctuations of cockles (Cerastoderma edule) and mussels (Mytilus edulis) in the Wash, 1894-1992: possible causal factors and relationships. Internal report, Ministry of Agriculture, Fisheries and Food, Lowestoft

Evans G, Collins M (1987) Sediment supply and deposition in the Wash. In: Doody P, Barnett B (eds) The Wash and its environment. Nature Conservancy Council, Peterborough, p 48-63

Fowler S (1987) The subtidal ecology of the Wash. In: Doody $P, B a r n e t t ~ B$ (eds) The Wash and its environment. Nature Conservancy Council, Peterborough, p 148-153

Hancock DA (1973) The relationship between stock and recruitment in exploited invertebrates. Rapp P-V Reun Cons lnt Explor Mer 164:113-131

HMSO London (1991) United Kingdom, sea fisheries statistics. HMSO, London

HMSO London (1994) United Kingdom, sea fisheries statistics. HMSO, London

HRS (Hydraulics Research Station) (1972) The Wash water storage scheme field studies, part one: data collected in 1971. Ex601, HRS, Wallingford

Jackson GA, Strathmann RR (1981) Larval mortality from offshore mixing as a link between precompetent and competent periods of development. Am Nat 118:16-26

Jones PD, Kelly PM (1982) Principal component analysis of the Lamb catalog of daily weather types. 1. Annual frequencies. J Climatol 2(2):147-157

Jorgensen CB (1981) Mortality, growth and grazing impact of a cohort of bivalve larvae, Mytilus edulis L. Ophelia 20: $185-192$
Ke X, Evans G, Collins MB (1996) Hydrodynamıcs and sediment dynamics of the Wash embayment, eastern England Sedimentology 43:157-174

Kendall MA, Bowman RS, Williamson P, Lewis JR (1982) Settlement patterns, density and stabilıty in the barnacle Balanus balanordes. Neth J Sea Res 16:119-126

Lamb HH (1972) British Isles weather types and a register of the daily sequence of circulation patterns 1861-1971. Geophys Mem (Lond) 116:1-85

Lewis JR (1972) Problems and approaches to baselıne studies in coastal communities. In: Ruvvo $\mathrm{M}$ (ed) Marine pollution and sea life. Fishing News Books, London

Munro JL, Jones AC, Dimitrious D (1968) Abundance and distribution of the larvae of the pink shrimp (Penaeus duodarum) on the Tortugas Shelf of Florida, August 1962 October 1964. Res Rep US Fish Wild Serv Fish Bull 67 $165-181$

Olaffson EB, Peterson CH, Ambrose WG Jr (1994) Does recruitment limitation structure populations and communities of macro-invertebrates in marine soft sediments: the relative significance of pre- and post-settlement processes. Oceanogr Mar Biol A Rev 32:65-109

Palutikof JP, Kelly PM, Davies TD, Halliday JA (1987) Impacts of spatial and temporal windspeed variability on wind energy output. J Climate Appl Meteorol 26(9):1124-1133

Rasmussen E (1973) Systematics and ecology of the Isefjord marine fauna (Denmark). Ophelia 11(1-2):1-507

Roughgarden J, Gaines S, Possingham H (1988) Recruitment dynamics in complex life cycles. Science 241:1460-1466

Roughgarden J, Pennington JT, Alexander S (1994) Dynamics of the rocky intertidal zone with remarks on generalization in ecology. Phil Trans R Soc Lond B 343:79-85

Salomons W, Bayne BL, Duursma EK, Forstner U (1988) Pollution of the North Sea. Springer-Verlag, Berlin

Savage RE (1956) The great spatfall of mussels in the River Conway estuary in spring 1940. Fishery Investigations, MAFF, London, Ser 1II, 20:1-21

Thiebaut E, Dauvin JC, Lagadeuc Y (1994) Horizontal distribution and retention of Owenia fusiformis larvae (Annelida: Polychaeta) in the Bay of Seine. J Mar Biol Ass UK 74: $129-142$

Thorson G (1950) Reproductive and larval ecology of marine bottom invertebrates. Biol Rev 25:1-45

Thorson G (1966) Some factors influencing the recruitment and establishment of marine benthic communities. Neth J Sea Res 3:267-293

Tiews K (1970) Synopsis of biological data on the common shrimp Crangon crangon (Linnaeus, 1758). FAO Fish Synopsis $57(4): 1167-1224$

Underwood AJ, Fairweather PG (1989) Supply-side ecology and benthic marine assemblages. Trend Ecol Evol 4:16-20

Wigley TML, Jones PD (1987) England and Wales precipitation: a discussion of recent changes in variability and an update to 1985 . J Climatol 7:231-246

Wildish DJ (1977) Factors controlling marine and estuarine sublittoral macrofauna. Helgoländer Wiss Meeresunters 30:445-454

Wood L, Hargis WJ (1971) Transport of bivalve larvae in a tidal estuary. In: Crisp DJ (ed) Fourth European Marine Biology Symposium, Bangor, Wales. Cambridge University Press, London

Young CM, Chia FS (1985) Abundance and distribution of pelagic larvae as influenced by predation, behaviour, and hydrographic factors. In: Giese AC (ed) Reproduction of marine invertebrates, Vol 9 . Blackwell Scientific, California 